\title{
Titanium-304L Stainless Steel Joining by Powder Metallurgical Uniaxial Pressing under Vacuum Conditions
}

\author{
M.B. Telli*, R. Yamanoglu and H.G. Sanli \\ Kocaeli University, Metallurgical and Materials Engineering Department, 41380 Kocaeli, Turkey \\ Ti-304L dissimilar metal joining was achieved by using powder metallurgical uniaxial pressing at $1000^{\circ} \mathrm{C}$ for \\ 10 minutes under vacuum. According to scanning electron microscope investigations, there were two different \\ intermetallic layer formations rich in $\mathrm{Fe}$, $\mathrm{Ti}$ and $\mathrm{Ni}$ content at joining interface. There were also some iron, nickel \\ and chromium diffusion into titanium but limited Ti diffusion into 304L. For the studied sample dimensions, \\ high residual stress appears as the result of big thermal expansion difference and large cool down step from high \\ joining temperature to room temperature. Chemical bonding was found to be strong enough to prevent total \\ delamination of joined Ti-304L sample, though cracking from surface defects at interface was observed. ANSYS \\ 14 Multiphysics modelling has shown that residual stress levels were in fact high. For studied sample profiles, \\ the 304L layer had residual maximum tensile principal stress around $332 \mathrm{MPa}$ at the outer edge of the joining \\ interface, Ti layer had lower residual minimal compressive principal stress around $-290 \mathrm{MPa}$ in the region close to \\ the outer edge. Corresponding equivalent plastic strains were of the order of $0.0017 \mathrm{~m} / \mathrm{m}$ for Ti layer and of the \\ order of $0.011 \mathrm{~m} / \mathrm{m}$ for 304L layer. Despite high residual stress levels, Ti-304L joining could be done at $1000{ }^{\circ} \mathrm{C}$ \\ with powder metallurgical uniaxial pressing.
}

DOI: 10.12693/APhysPolA.134.37

PACS/topics: Ti, 304L, dissimilar metal joining, interfacial reactions, powder metallurgy, residual stress strain modelling

\section{Introduction}

Titanium to 304L stainless steel joining is important for many industries and is especially needed for chemical industry [1]. For joining titanium and 304L stainless steel laser, friction, explosive, spark plasma and stir welding were among the explored techniques, however brittle TiFe intermetallic formations are often observed [2-6].

Powder metallurgical uniaxial pressing technique is successfully used for joining of dissimilar metals such as nickel to iron and aluminum alloy to magnesium $[7,8]$. If Ti-304L dissimilar metal joining could be done without extensive brittle Fe-Ti intermetallic formations and failure, powder metallurgical uniaxial pressing could be a viable technique for such joining. In current literature, there are not many reported studies for dissimilar metal joining of titanium to $304 \mathrm{~L}$ stainless steel by powder metallurgical uniaxial pressing.

In this study, joining of titanium to 304L by employing powder metallurgical uniaxial pressing technique under vacuum is provided. Interfacial chemical reactions between titanium and 304L are investigated by employing scanning electron microscope (SEM) and energy dispersive spectroscopy (EDS). Residual stress and strains for joined layers were modelled by using ANSYS 14 Multiphysics finite element simulation software. Finally, some important points for successful joining of dissimilar titanium to $304 \mathrm{~L}$ stainless steel with powder metallurgical uniaxial pressing technique are discussed.

\footnotetext{
* corresponding author; e-mail mustafa.telli@kocaeli.edu.tr
}

\section{Experimental procedure}

Ti powders having particle size between 150 and $230 \mu \mathrm{m}$ (Alfa Aesar, 99.5\% purity) and 304L stainless steel powders having particle size lower than $150 \mu \mathrm{m}$ (Alfa Aesar) were used in metallurgical uniaxial pressing. Graphite die (having $20 \mathrm{~mm}$ inner diameter) and punches were used for uniaxial pressing of powders. Prior to pressing, graphite die and punches were spray coated with hexagonal boron nitride to prevent carbon contamination of pressed powders.

Ti powder was first placed into graphite die and leveled loosely. Then, 304L stainless steel powder was placed on top of the leveled $\mathrm{Ti}$ powder and leveled loosely again. Graphite die was inserted into uniaxial press and evacuated until vacuum of $10 \mathrm{~Pa}$ was achieved. Powders were then pressed uniaxially under pressure of $40 \mathrm{MPa}$. While pressure was applied under vacuum, system was heated to $1000^{\circ} \mathrm{C}$ with a heating rate of $50^{\circ} \mathrm{C} / \mathrm{min}$., kept at $1000^{\circ} \mathrm{C}$ for $10 \mathrm{~min}$. and finally cooled down to room temperature with a cooling rate of $50^{\circ} \mathrm{C} / \mathrm{min}$.

Chemical reactions occurring at $\mathrm{Ti}-304 \mathrm{~L}$ joining interface were investigated using a JEOL6060 SEM with secondary electron imaging mode and by EDS analysis. Cross section sample was prepared for the investigation of the joining interface. Pressed sample was first encapsulated into a polymer mold and then cut slowly using a diamond saw to reveal the interface and grinded with 600 and 1000 grid SiC grinding paper. Prior to SEM investigation, a slight $\mathrm{Au}$ sputtering was applied to prevent any charging effects.

Residual maximal, minimal principal and equivalent von Mises stresses and residual equivalent plastic strains were modelled by employing ANSYS 14 Multiphysics software. Modelling was done considering strain harden- 
ing effects and plastic deformations. Table I shows material parameters used during modelling. Residual stress and strains were developing due to differences in material properties and due to cooling down of joined sample from $1000^{\circ} \mathrm{C}$ to $20^{\circ} \mathrm{C}$. Sample shape and sizes assumed for modelling were disks of a diameter of $20 \mathrm{~mm}$ and thickness of $5 \mathrm{~mm}$ for titanium and $1 \mathrm{~mm}$ for 304L.

TABLE I

Material properties used for residual joining stress calculations.

\begin{tabular}{l|c|c}
\hline \hline \multicolumn{1}{c|}{ Material property } & Ti & $304 \mathrm{~L}$ \\
\hline Thermal expans. coef. $\alpha[\mathrm{m} / \mathrm{m}]$ & $10.1 \times 10^{-6}$ & $18.7 \times 10^{-6}$ \\
Young modulus $E[\mathrm{~Pa}]$ & $116 \times 10^{9}$ & $193 \times 10^{9}$ \\
Poison ratio $v$ & 0.34 & 0.24 \\
Yield strength $\sigma y[\mathrm{~Pa}]$ & $240 \times 10^{6}$ & $280 \times 10^{6}$ \\
True stress $\sigma_{\text {true }}$ level $[\mathrm{Pa}]$ & $550 \times 10^{6}$ & $1700 \times 10^{6}$ \\
True strain $\varepsilon_{\text {true }}$ level $[\mathrm{m} / \mathrm{m}]$ & 0.2 & 1.15
\end{tabular}

\section{Results and discussion}

Figure 1a and b shows scanning electron microscope images of joining cross section for sample uniaxially hot pressed at $1000^{\circ} \mathrm{C}$ for $10 \mathrm{~min}$. Figure 1a illustrates that Ti-304L joining could be done without total delamination of layers, though there was a crack formation at the outer edge. Figure 1b shows more clearly that crack formation was originating from a surface defect existing at the outer edge of joined interface. This suggested that residual joining stresses were high at the edge of joining interface. Middle joining regions were crack free and this suggested that chemical bonding was good and strong enough to resist any residual stress levels developed in this region.
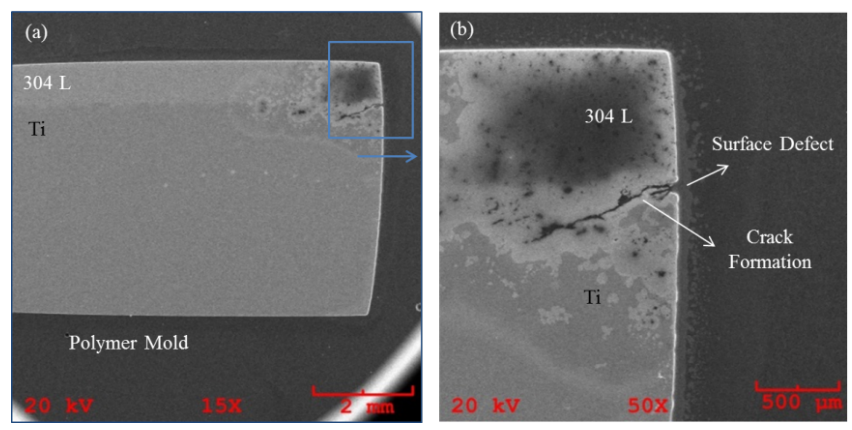

Fig. 1. Scanning electron microscope images of sample uniaxially hot pressed at $1000^{\circ} \mathrm{C}$ for 10 min.: (a) secondary electron image taken at $15 \times$ magnification, showing sample cross section, (b) secondary electron microscope image taken at higher $50 \times$ magnification, showing crack formation originating from the outer edge of Ti-304L joining interface.

Figure $2 \mathrm{a}$ and $\mathrm{b}$ provides higher magnification scanning electron microscope images of middle section where no macro cracking was observed for sample uniaxially hot pressed at $1000^{\circ} \mathrm{C}$ for 10 min. Figure 2a illustrates that there was no sign of micro cracking at middle joining regions, suggesting chemical bonding was good and strong enough to resist any developed residual stress levels. Figure 2b presents two intermetallic layer formations (marked as spots 2 and 3) at joining interface. Table II presents EDS analysis results at spot positions close to joining interface.

Though two intermetallic layers had high Fe, Ti and Ni contents, the intermetallic layer that was formed closer to $304 \mathrm{~L}$ side (at spot 2) had higher Fe and lower Ti contents, compared to the intermetallic layer formed closer to the Ti side (at spot 3 ). There was also significant $\mathrm{Fe}$ and some $\mathrm{Cr}$ and $\mathrm{Ni}$ diffusion into $\mathrm{Ti}$ side according to EDS analysis at spot 1. However, Ti diffusion into the 304L side was limited, according to EDS results obtained at spot 4 .
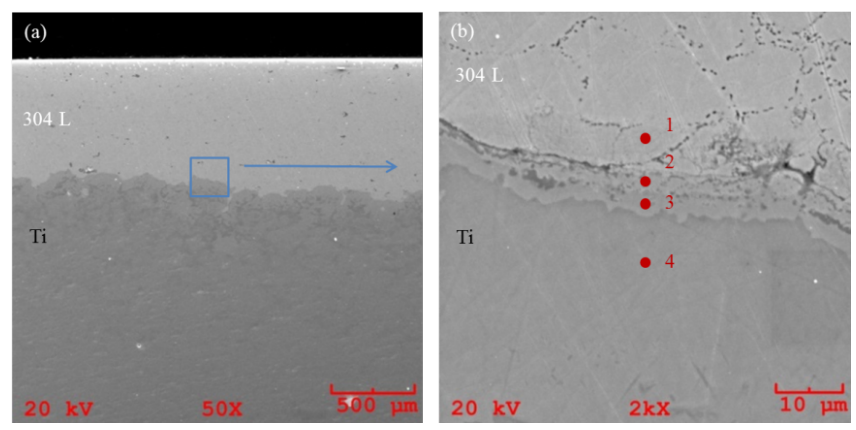

Fig. 2. Scanning electron microscope images taken from middle section of sample uniaxially hot pressed at $1000{ }^{\circ} \mathrm{C}$ for $10 \mathrm{~min} .:$ (a) secondary electron image taken at 50× magnification, (b) secondary electron image taken at higher $2000 \times$ magnification, showing positions of spots of the EDS analyses.

TABLE II

Spot EDS analyses of Ti-304L joining interface.

\begin{tabular}{c|c|c|c|c}
\hline \hline $\begin{array}{c}\text { EDS } \\
\text { position }\end{array}$ & $\begin{array}{c}\mathrm{Fe} \\
\text { [wt.\%] }\end{array}$ & $\begin{array}{c}\mathrm{Cr} \\
\text { [wt.\%] }\end{array}$ & $\begin{array}{c}\mathrm{Ni} \\
\text { [wt.\%] }\end{array}$ & $\begin{array}{c}\mathrm{Ti} \\
\text { [wt.\%] }\end{array}$ \\
\hline Spot1 & 70.64 & 17.17 & 10.18 & 0.63 \\
Spot2 & 42.78 & 3.98 & 8.08 & 44.29 \\
Spot3 & 22.16 & 1.67 & 10.39 & 64.94 \\
Spot4 & 14.71 & 3.13 & 2.50 & 78.97
\end{tabular}

Figure 3 shows the residual maximum and minimum principal stress of joined sample with given dimensions, modeled by employing ANSYS 14 Multiphysics software. Figure 3a shows that the highest tensile residual maximum principal stress observed at the joining interface towards the outer edge is of the order of $332 \mathrm{MPa}$ for 304L. Figure 3b illustrates that Ti has a slightly lower but still high compressive residual principal minimum stresses of the order of $-290 \mathrm{MPa}$, observed at joining interface close to the outer edge.

This stress occurs mainly due to $304 \mathrm{~L}$ layer having higher thermal expansion coefficient $\left(18.7 \times 10^{-6}\right)$ than 
the Ti layer $\left(10.1 \times 10^{-6}\right)$. During cooling down form the joining temperature, 304L layer was prevented from shrinking freely due to chemical bonding to $\mathrm{Ti}$ layer, causing high tensile residual maximum principal stress in 304L. The Ti layer, on the other hand, was forced to shrink more than its free shrinking, causing high compressive residual minimum principal stress.

High tensile residual stresses at joining interface of 304L layer at the outer edge, observed using modelling, agrees well with the SEM investigation, showing that crack formation originated from a defect at outer edge of joining interface and thus showing that high residual stress was developed in the 304L layer.
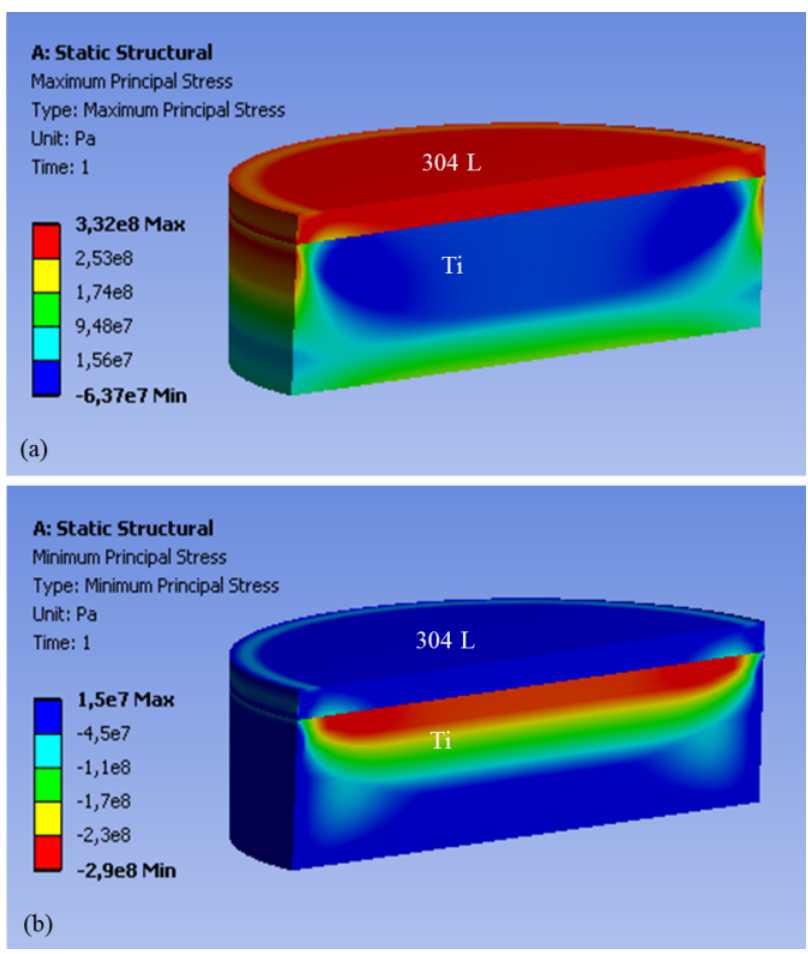

Fig. 3. Residual joining stress levels of Ti-304L joining sample modeled by employing ANSYS 14 Multiphysics software: (a) maximum residual principal stress for joining cross section, (b) minimum residual principal stress for joining cross section.

Figure 4 shows residual equivalent von Mises stress and equivalent plastic strains of joined sample modeled by employing ANSYS 14 Multiphysics software. Figure 4a illustrates that residual equivalent von Mises stresses were high for both, the 304L layer (around $280 \mathrm{MPa}$ towards the outer edge and around $290 \mathrm{MPa}$ in the central region of joining interface) and the Ti layer (around $260 \mathrm{MPa}$ close to outer edge of joining interface).

Big thermal expansion difference of considered materials $\left(10.1 \times 10^{-6}\right.$ for $\mathrm{Ti}$ and $18.7 \times 10^{-6}$ for $\left.304 \mathrm{~L}\right)$ and wide range cooling step (from $1000^{\circ} \mathrm{C}$ to $20^{\circ} \mathrm{C}$ ) were main reasons for observing such high residual stress levels for the studied sample sizes.

Figure $4 \mathrm{~b}$ shows that the corresponding residual equiv- alent plastic deformations for 304L layer is of the order of $0.011 \mathrm{~m} / \mathrm{m}$ near the central region of joining interface for $304 \mathrm{~L}$ layer and of the order of $0.017 \mathrm{~m} / \mathrm{m}$ close to outer region of the joining interface for Ti layer. Since Ti had slightly lower yield strength of $240 \mathrm{MPa}$ compared to 304L layer, having yield strength of $280 \mathrm{MPa}$, Ti layer had slightly higher equivalent plastic strains compared to 304L layer for observed rather high residual stress levels.

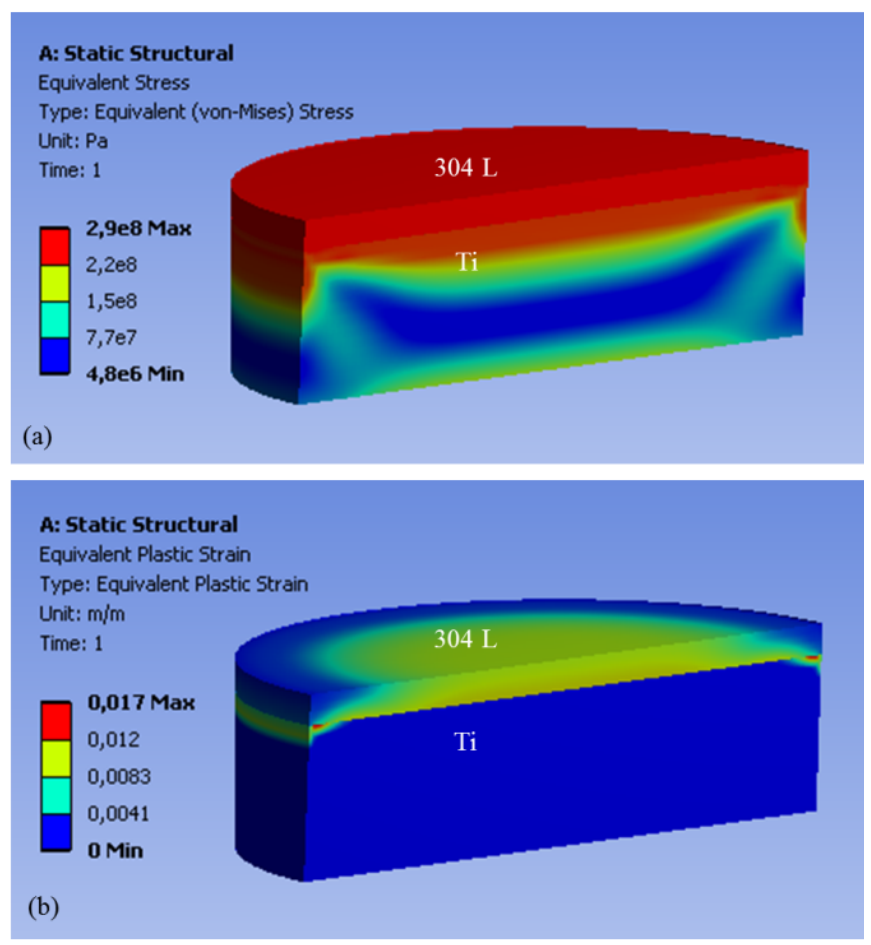

Fig. 4. Residual equivalent von Mises stress and plastic strain levels of Ti-304L joining sample modeled by employing ANSYS 14 Multiphysics simulation software: (a) residual equivalent von Mises stress for joining cross section, (b) residual equivalent plastic strain for joining cross section.

Residual stress and strains of joined sample were affected by differences in material properties, such as difference in thermal expansion, strain hardening rates and uniaxial pressing processing conditions, like the large cooling down step. For successful joining, the developed residual stress levels need to be lower than the level at which chemical bonding could resist. Selecting sample dimensions to lower residual stresses, such as using smaller diameter and thicknesses, would lower the residual stresses and may reduce crack formation from surface defects as well.

\section{Conclusions}

Ti-304L dissimilar joining was achieved by employing uniaxial powder pressing at $1000^{\circ} \mathrm{C}$ for $10 \mathrm{~min}$. at $10 \mathrm{~Pa}$ vacuum. SEM investigations have shown that bonding between Ti and 304L layers was good and strong enough to resist cracking if residual stress levels were kept low. 
Spot EDS analyses have shown that there were two different intermetallic layer formations having high $\mathrm{Fe}$, $\mathrm{Ti}$ and $\mathrm{Ni}$ contents at joining interface and that there is a significant $\mathrm{Fe}$ and some $\mathrm{Cr}$ and $\mathrm{Ni}$ diffusion into the Ti side.

ANSYS14 Multiphysics modelling of residual stress has suggested that joining interface experienced rather high residual stress levels due to big difference in thermal expansion of materials of the joined layers and due to large amplitude of the cooling step. Highest tensile residual maximum principal stress levels were of the order of $332 \mathrm{MPa}$ for 304L and were observed at the outer edge of the joining interface, where crack formation from a surface defect between 304L and Ti layer was observed.

Ti had slightly lower but still high compressive residual principal minimum stresses of the order of $-290 \mathrm{MPa}$ at joining interface close to outer edge. Residual equivalent plastic deformations of the order of $0.011 \mathrm{~m} / \mathrm{m}$ near the central region of the joining interface were lower for 304L layer compared to Ti layer, having equivalent plastic strain levels of the order of $0.017 \mathrm{~m} / \mathrm{m}$ close to the outer region of the joining interface, due to $\mathrm{Ti}$ having a slightly lower yield strength compared to 304L. For successful joining the interface needs to be kept free of defects and the developed residual stress levels needed to be kept low.

\section{Acknowledgments}

This study was financially supported by scientific research project 2014-87 of Kocaeli University, Turkey.

\section{References}

[1] M. Fazel-Najafabadi, S.F. Kashani-Bozorg, A. ZareiHanzaki, Mater. Design 32, 1824 (2011).

[2] C.M. Rejil, C. Sharan, S. Muthukumaran, M. Vasudevan, Trans. Nonferrous Met. Soc. China 26, 2067 (2016).

[3] N. Kahraman, B. Gulenc, F. Findik, J. Mater. Process. Technol. 169, 127 (2005).

[4] N.N. Kumar, G.D.J. Ram, S.S.B. Bhattacharya, H.C. Dey, S.K. Albert, Trans. Indian Inst. Metals 68, 289 (2015).

[5] K. Ishida, Y. Gao, K.N.N. Kumar, G. Nagatsuka, M. Takahashi, K. Nakata, J. Alloys Compd. 630, 172 (2015).

[6] A. Fuji, K. Ameyama, T.H. North, J. Mater. Sci. 31, 819 (1996).

[7] R. Yamanoglu, E. Efendi, Mater. Test. 58, 151 (2016).

[8] R. Yamanoglu, Acta Metall. Sin. Engl. 28, 1059 (2015). 